\title{
NADPH-DIAPHORASE HISTOCHEMISTRY SELECTIVELY STAINS PERIPHERAL AND CENTRAL SENSORY STRUCTURES OF LUMBRICID EARTHWORMS
}

\author{
Zsuzsanna Solt ${ }^{1}$, Andrea ZsomboK ${ }^{2}$, Edit Pollák ${ }^{1}$ and LÁszló MolnáR ${ }^{1 *}$ \\ ${ }^{1}$ Department of Comparative Anatomy and Developmental Biology, University of Pécs, Pécs, Hungary \\ ${ }^{2}$ Department of Physiology, School of Medicine, Tulane University, New Orleans, USA
}

(Received: March 10, 2016; accepted: March 31, 2016) By means of whole mount NADPH-diaphorase histochemistry the distribution pattern of primary sensory
cells (PSC) and the pathway of their central processes in the ventral nerve cord (VNC) ganglia were
investigated in the lumbricid earthworms, Eisenia fetida and Lumbricus terrestris. The distribution pat-
tern of the stained structures seemed to be the same in both species investigated. Strong labelling occurred
in sensory fibre branches of segmental nerves and in each of the sensory longitudinal axon bundles of
VNC ganglia. Based on their anatomical location some NADPH-d positive central sensory cells were
identified from among which the putative tactile receptors were characterized by constant, strong staining.

Keywords: Earthworm - ventral nerve cord ganglia - sensory longitudinal axon bundles - central sensory cells - NADPH-diaphorase histochemistry

\section{INTRODUCTION}

The earthworms' central nervous system (CNS) consists of a cerebral, a subesophageal and numerous ventral nerve cord (VNC) ganglia, from among which the latter ones situated in the mid-body (postclitellar) segments are uniformly organized [8-10]. They have three segmental nerves each innervating peripheral organs and tissues further receiving input from both intero- and exteroreceptors.

During the last decades the functional anatomy of VNC ganglia was in the focus of several studies. The exact location of a few cell bodies (central sensory cells (CSC), giant motoneurons and somata of giant axons and interneurons) was described. The anatomical position of the longitudinally directed interneuronal tracts and the central sensory pathways, the so-called sensory longitudinal axon bundles (SLABs), have also been revealed [8-10]. The latter structures compiled from the central projections of primary sensory cells are located in the body wall epithelium [18]. Moreover the peripherally directed axons of the CSCs also run in them [5]. Some CSCs, characterized by distinctive anatomical positions, was identified as proprioreceptors which mediate pressure (P cells) and tactile ( $\mathrm{T}$ cells) stimuli of the body wall

\footnotetext{
*Corresponding author; e-mail address: molnar@gamma.ttk.pte.hu
} 
to the CNS, while the epithelial sensory cells are excited by mechanical and chemical irritation [18].

Primary sensory cells of Clitellata worms are heterogeneous in size, form and chemical composition. They contain various neuroactive compounds like dopamine $[20,23]$, serotonin, histamine, GABA and some neuropeptides, e.g. proctolin, FVRIamide and Eisenia tetradecapeptide [2, 17, 19] indicating that the sensory system operates with various transmitters [2].

The gaseous neuronal messenger, the nitric oxide (NO) is widely distributed in sensory pathways of both vertebrates $[7,18,22]$ and invertebrates $[3,6,11]$, suggesting the significance of $\mathrm{NO}$ in the mediation of various (both external and internal) stimuli. The occurrence of putative NO-producing (NADPH-d positive) structures was partially described in the VNC of Lumbricus terrestris [12], however, without exact anatomical characterization.

The aim of this study was to map the distribution of the putative NO-producing structures in the body wall epithelium and VNC ganglia of lumbricid earthworms and to compare the anatomical positions of these labelled structures with other neurochemically or anatomically identified ones, to conclude what functions could be mediated by NO in the nervous system of earthworms.

\section{MATERIALS AND METHODS}

\section{Animals}

Ten adult specimens of both Eisenia fetida Sav. and Lumbricus terrestris L. (Annelida, Clitellata), respectively, were used in all experiments. The former species was kept in a breading stock at standard laboratory conditions (food ad libitum, moisture content of the substratum was approximately $60 \%$, temperature $20{ }^{\circ} \mathrm{C}, 12$ hours-long darklight cycle) from which the worms were hand-sorted and placed on wetted filter paper and kept at room temperature for 2 days before the experiments. Specimens of L. terrestris were collected from their natural habitat and they were kept on filter paper in a wetted chamber at $8-10{ }^{\circ} \mathrm{C}$.

After anaesthesia with carbon dioxide and chilling, VNC ganglia situated in 7-10 postclitellar segments of the body were cut off and used for histochemical examinations.

\section{NADPH-diaphorase histochemistry}

To identify the putative NO producing (NADPH-d positive) neural structures dissected parts of the body wall and VNC ganglia were fixed with $4 \%$ paraformaldehyde (PFA) diluted in $0.1 \mathrm{M}$ phosphate buffer (PB) for 3 hours at $4{ }^{\circ} \mathrm{C}$, as suggested earlier [22]. After fixation, thorough washing (six changes of $\mathrm{PB}$ ) was applied and the samples were digested with $1 \%$ trypsine (dissolved in $0.1 \mathrm{M}$, TRIS buffer, $\mathrm{pH} 7.6$, at $37^{\circ} \mathrm{C}$ ) for 10 minutes to increase the permeability of the well-developed ganglion 
sheet. Subsequent to digestion, samples were treated with $1 \%$ Triton-X 100 in $0.1 \mathrm{M}$ PB overnight. Thereafter they were incubated in a freshly prepared mixture of 0.25 $\mathrm{mg} / \mathrm{ml}$ nitro blue tetrazolium (NBT) or 2-(2'-benzothiazolyl)-5-styril-3-(4'-phthalhydrazidyl) tetrazolium chloride (BSPT) and $1 \mathrm{mg} / \mathrm{ml} \beta-\mathrm{NADPH}$ (dissolved in $0.1 \mathrm{M}$ $\mathrm{PB}, \mathrm{pH}$ 8.0) in dark at $37^{\circ} \mathrm{C}$. All chemicals were purchased from Sigma (Budapest, Hungary). The staining was controlled under light microscope and interrupted by washing in PB. In control experiments either NADPH or NBT was omitted from the incubating solution, after which no specific staining was seen in the samples.

The NBT-formazan stained samples were postfixed in PFA overnight, washed in $\mathrm{PB}$, cleared in glycerol and investigated as whole mounts. The BSPT-formazan labelled VNC ganglia were postfixed in ice-cold 1\% glutaraldehyde overnight, washed in $\mathrm{PB}$ and osmicated in $1 \% \mathrm{OsO}_{4}$ dissolved in $0.1 \mathrm{M}$ PB for 2 hours in dark at $4{ }^{\circ} \mathrm{C}$. After dehydration the samples were embedded in Durcupan ACM and $2.5 \mu \mathrm{m}$ thick sections were cut for light microscopy. In order to determine the exact anatomical positions of NADPH-d positive structures in the VNC ganglia, both whole mount preparations and resin sections were investigated by a Nikon microscope fitted with a UFX camera.

\section{RESULTS}

NADPH-d histochemistry resulted in a specific staining in both the body wall epithelium and VNC ganglia and in all of their segmental nerves of both species. The anatomical position of labelled neural structures was found to be definitely the same in all investigated body parts of both E. fetida and L. terrestris, suggesting that (1) a constant neuron set expresses NADPH-d in mature specimens and (2) there is no significant variation in the distribution pattern of the NADPH-d positive structures of the body wall and VNC ganglia in the investigated species. However, in E. fetida the background of histochemical staining was significantly higher (Fig. 1) than in L. terrestris therefore to show characteristic location and pattern of labelled structures in Lumbricid worms, it will be presented in sections obtained from $L$. terrestris.

In the body wall epithelium solitary sensory cells and grouped ones located in sensillas were strongly stained (Fig. 2). Their central processes could easily be followed both in whole mount preparations and sections of all segmental nerves and VNC ganglia (Figs 3,4). Their most conspicuous structures were strongly stained SLABs that were characterized by constant diameter and run without interruption from ganglion to ganglion. The exact number and termination of fibres could not be defined with light microscopic observation because of their overlapping and small diameter, but it was clearly seen that sensory fibres of the $1^{\text {st }}$ and $3^{\text {rd }}$ segmental nerves entered into the ventrolateral SLABs that surrounded the ventral giant axons while the fibres of the $2^{\text {nd }}$ segmental nerves entered into the ventromedial SLABs (Fig. 3C). In semi-thin sections NADPH-d activity was found in ventromedial-, intermediomedial-, intermediolateral- and dorsal SLABs, too (Fig. 3D-F). Except for SLABs, no other labelled fibre-branches were found but a few heavily stained single axons were seen in the 


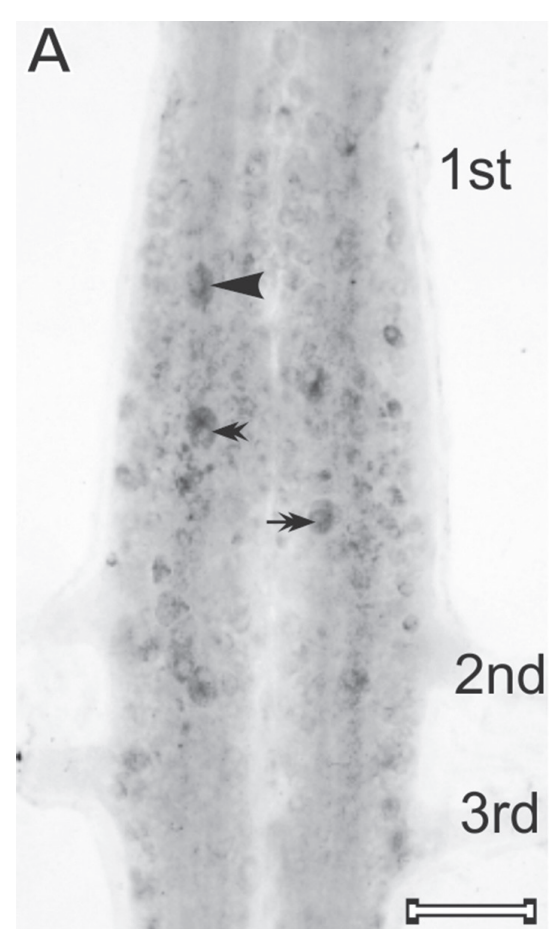

Fig. 1. Strongly stained NADPH-d positive perikarya in the whole mount preparation of a VNC ganglion in E. fetida (ventral surface of the ganglion is in the focus). Note pattern of the labelled structures seems to be identical with that found in L. terrestris (see Fig. 4!). Same symbols label putative identical structures in E. fetida and L. terrestris, respectively. Scale bar: $100 \mu \mathrm{m}$
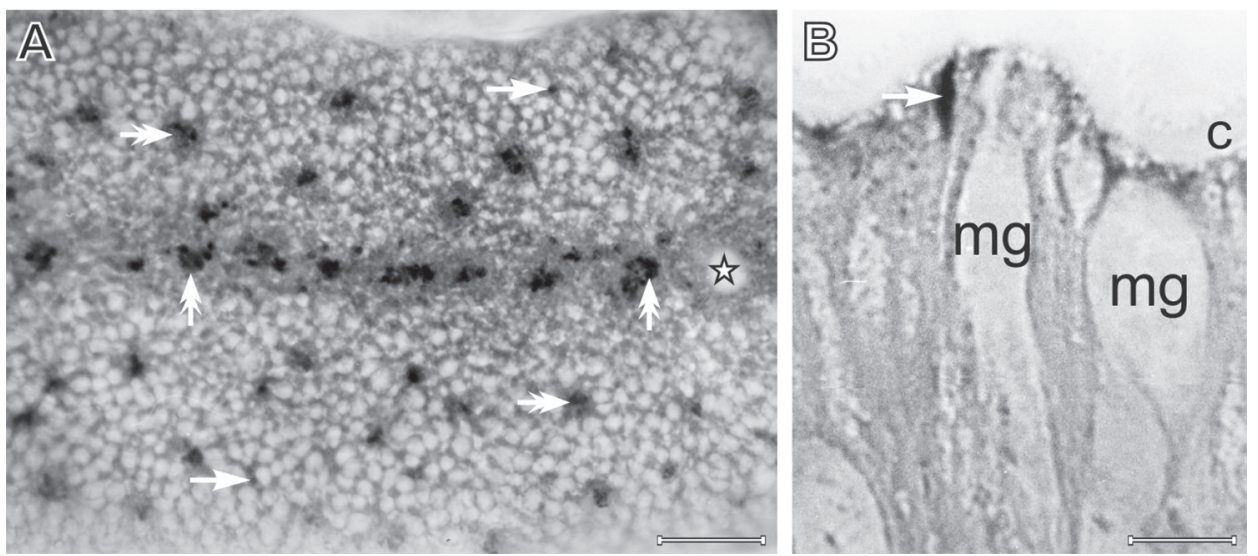

Fig. 2. NADPH-d positive primary sensory cells in the body wall epithelium of $L$. terrestris. A shows the distribution pattern of labelled cells in a segment. Note most of the primary sensory cells are grouped into sensillas (double arrows) and large sensillas are located in the setae row. The number of the solitary sensory cells (arrows) is low in midbody segments. Anterior is the top. Scale bar: $100 \mu \mathrm{m}$. B shows histological characteristics of a labelled solitary sensory cell (arrow) located under the cuticle (c) close to mucous gland cells (mg). Scale bar: $10 \mu \mathrm{m}$ 
dorsomedial and dorsolateral interneuron tracts. These axons are usually characterized by small diameter; however, a pair of heavily stained medium size axons running in the dorsolateral tracts also occurred (Fig. 3). At this stage of our experiments neither their origin nor their destination or synaptic connections could be identified.
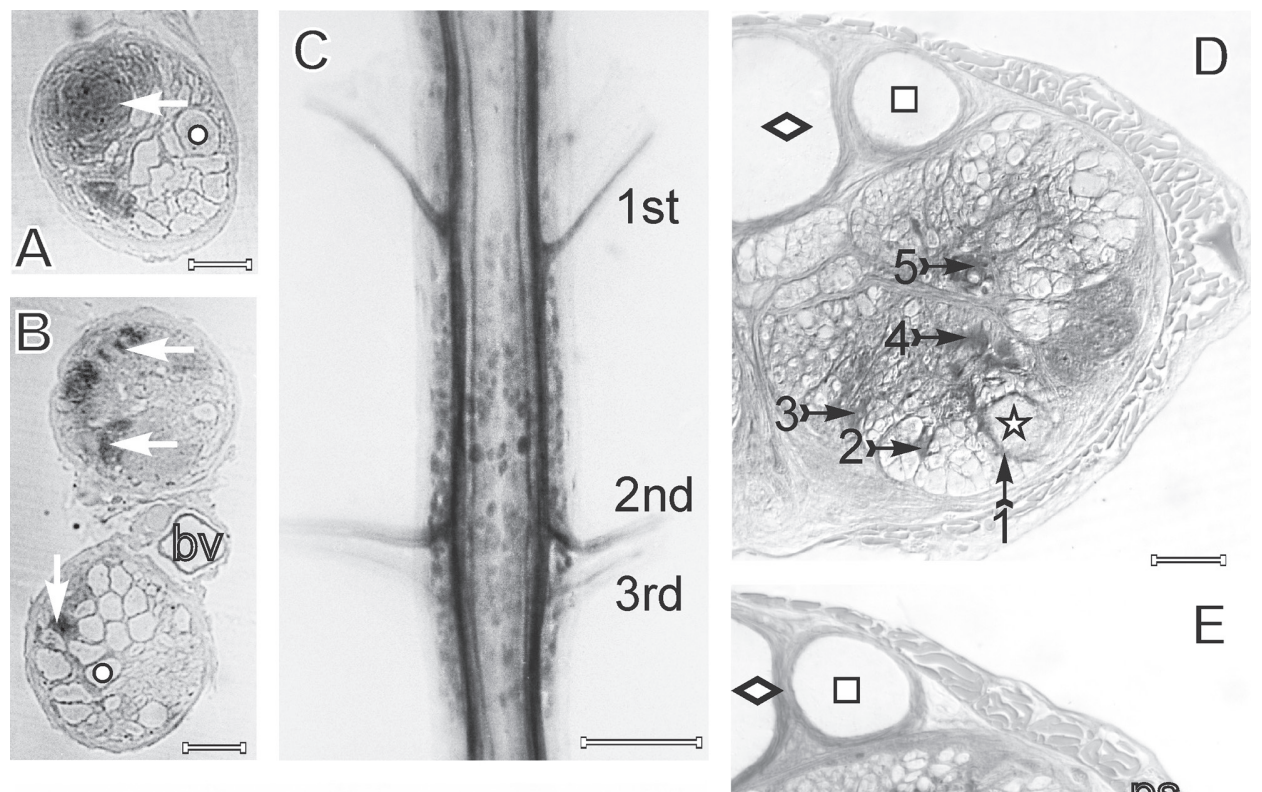

$E$
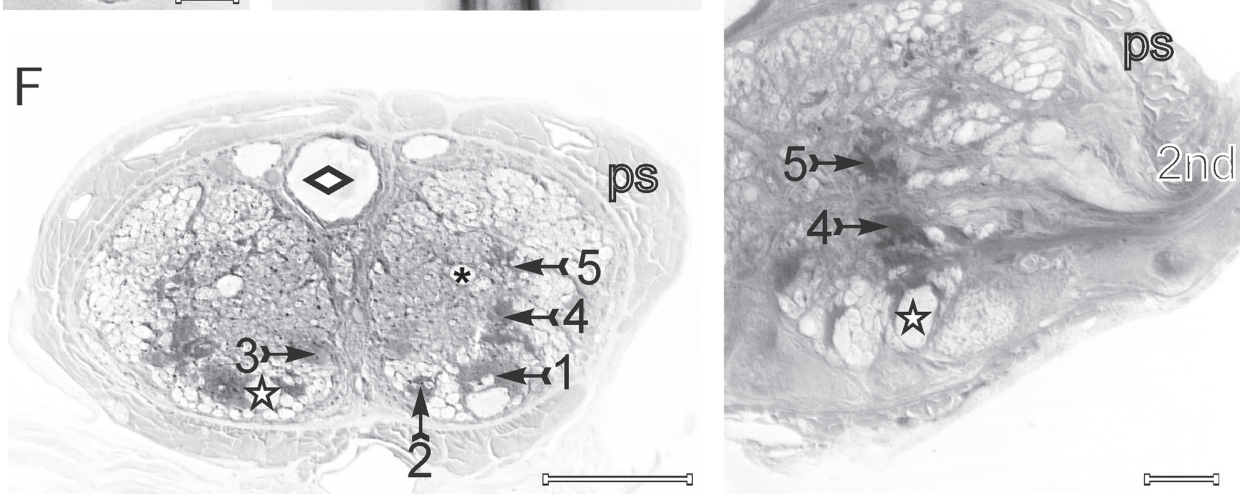

Fig. 3. Peripheral (A, B) and central (C-F) pathways of NADPH-d stained processes of primary sensory cells in L. terrestris (ventral surface of the ganglion is in the focus). Note extremely high numbers of sensory fibres (arrows) are located in the $1^{\text {st }}(\mathrm{A})$ and $2^{\text {nd }}(\mathrm{B})$ segmental nerves while in the $3^{\text {rd }}$ one mainly contains motor processes (circles). Bv: blood vessel. Scale bars: $5 \mu \mathrm{m}$. In whole mount preparation (C) the most conspicuous structures are the heavily stained longitudinal sensory axon bundles. Scale bar: 100 $\mu \mathrm{m}$. Cross-sections of the ganglion behind the $1^{\text {st }}$ segmental nerves (D), at the level of the $2^{\text {nd }}$ segmental nerve $(E)$ and at the commissural part $(\mathrm{F})$ show anatomical location of labelled ventrolateral (1),ventromedial (2), intermediomedial (3), intermediolateral (4) and dorsolateral (5) SLBs. ps: perineural sheet, white asterisk: ventral giant axon, square: lateral giant axon, rhombus: median giant axon, black asterisk: large segmental interneuron. Strongly stained perikarya (double arrow and arrowhead) are identical with those ones showed in Fig. 5C. Scale bars: $100 \mu \mathrm{m}(\mathrm{D}, \mathrm{E})$ and $50 \mu \mathrm{m}(\mathrm{F})$ 
Two distinct groups of NADPH-d positive somata could be distinguished in VNC ganglia: the first contained heterogeneously labelled cells characterized by moderate or week enzyme activity, while the second group gave constant strong staining in each preparation (Fig. 4). The second group consisted of three pairs of heavily stained

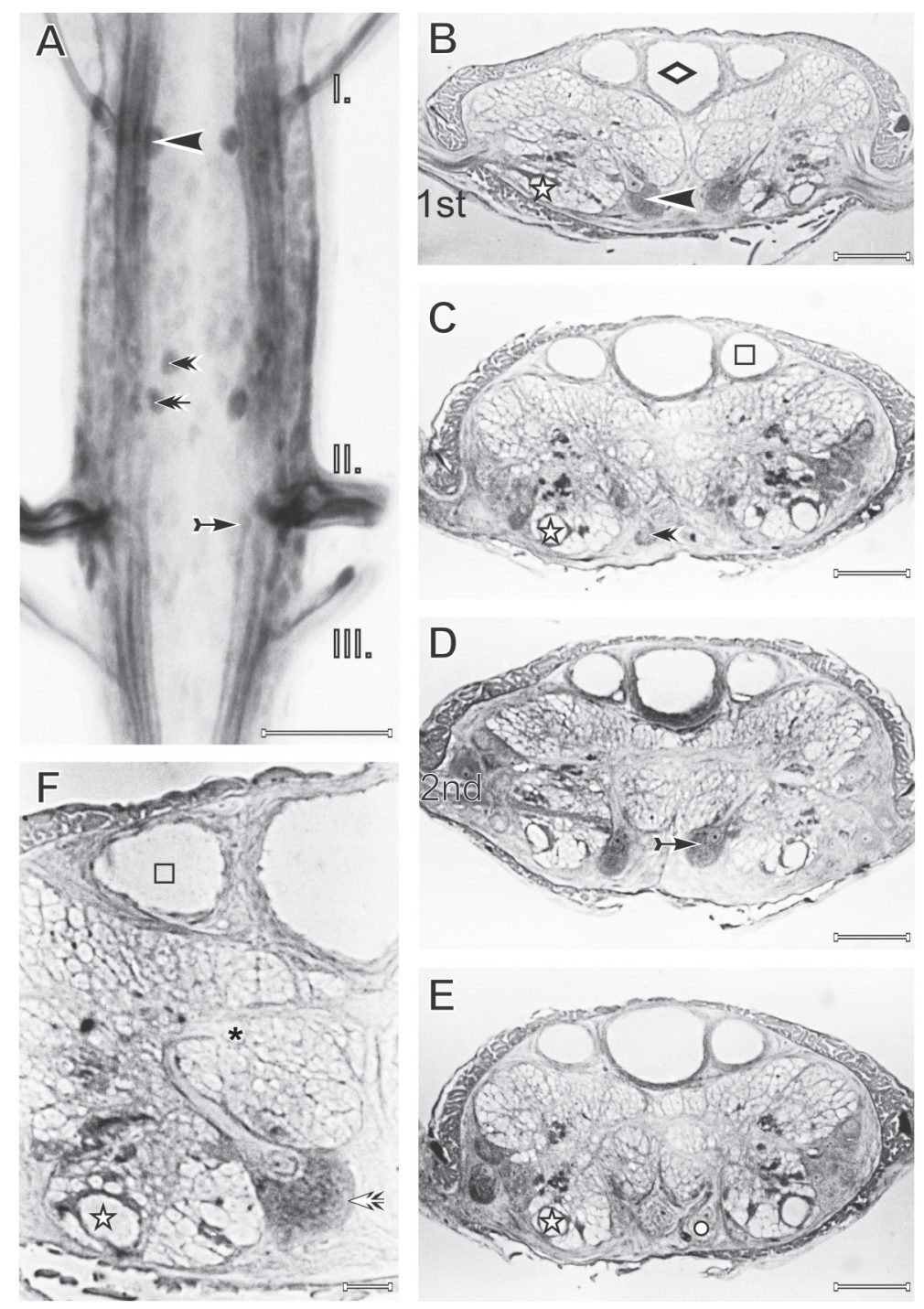

Fig. 4. Anatomical locations of the heavily stained perikarya in the whole mount preparation (ventral surface of the ganglion is in the focus) (A) and its sections (B-F) of L. terrestris. Same symbols label identical structures in pictures. Square: lateral giant axon, rhombus: median giant axons, asterisk: ventral giant axon, circle: unstained somata, black asterisk: large segmental interneuron. Scale bars: $100 \mu \mathrm{m}(\mathrm{A})$, $50 \mu \mathrm{m}(\mathrm{B}-\mathrm{E})$ and $10 \mu \mathrm{m}(\mathrm{F})$ 
neurons. They were situated in the middle region of the ganglia closely to the VL-SLABs. In the best samples, even the connection of their axons to the ipsilateral SLABs could be seen (Fig. 4).

\section{DISCUSSION}

By means of immunohistochemistry the occurrence of NOS positive structures in the body wall epithelium of $L$. terrestris was described in details by Licata et al. [14], suggesting that NO had a multitude of biological actions. However, they identified NOS activity in both ortho- and metachromatic mucous gland cells as well, our NADPH-d histochemical results do not support their findings. Since NADPH-d activity is a characteristic histochemical marker of NOS [24] the conflict warrants further investigations. The presence and pattern of NADPH-d labelled neurons were shown in the CNS of leeches [13], which are closely related to earthworms, so the organization of the VNC ganglia seems to be similar, but the staining was restricted to perikarya and no characteristic labelling was described in the neuropile.

In contrast to an earlier work focused on the investigation of the NADPH-d stained structures of earthworm CNS [12], this study presented not only an account of NADPH-d reactivity of several structures in earthworms' VNC ganglia but also the exact anatomical positions of some distinct structures.

The identification of SLABs, based on their location and anatomical characteristics is a feasible task. All of them receive inputs from primary sensory cells, located in the body wall epithelium, via ipsilateral segmental nerves and run in the ipsilateral hemiganglion which is characteristic of the central sensory pathways of the earthworms [8]. Since the above-mentioned primary sensory cells are mechano- and chemoreceptors [16], and neurophysiological experiments proved that both chemo- and mechanoreceptive information entered the CNS via all of the segmental nerves [16], at this stage of our experiments we could only conclude that the putative NOS-expressing fibres mediate both kinds of sensory stimuli. NOS/NADPH-d activity was shown in both chemo- and mechanoreceptors and their central projections in both invertebrates $[1,6,11]$ and vertebrates $[7,18,22]$.

Several studies described the neurochemical heterogeneity of primary sensory cells and the presence of different neurotransmitters in the fibre sets of sensory pathways in earthworms [for review see 2], while in the CNS indolamine and catecholamine containing SLBs were shown [4]. The position of the latter structures closely resembled to those of the VL-, and VM-SLBs, suggesting that in these SLBs both types of neurotransmitters could co-localize with NOS/NADPH-d. Co-localization of cathecolamines and NADPH-d was found in the CNS of various species, e.g. in the lizard, Gekko gecko [22], and the frog, Rana perezi [18]. However, considerable variations could be found between species, for instance in urodeles no colocalization of NADPH-d with tyrosine hydroxylase (as a marker for catecholamines) was revealed [7]. 
In contrast to the SLABs, it is more complicated to compare the positions of the stained perikarya of VNC ganglia with earlier functionally identified cells. The anatomical location of the two pairs of strongly stained cells and their connections to the ipsilateral SLBs strongly suggest that they are identical with tactile sensitive cells which represent a distinct neuron set of CSCs in earthworms' CNS. Tactile sensitive cells send their processes to the periphery via the $1^{\text {st }}$ and $3^{\text {rd }}$ segmental nerves $[5,8]$; the processes of the strongly labelled cells enter the VL-SLBs that connect to the periphery via the above-mentioned structures.

From among the heterogeneously labelled cell population, the positions of distinct neuron sets situated at lateral and dorsolateral position in front of the root of the $2^{\text {nd }}$ segmental nerves resemble to the pressure sensitive CSCs [5]. However, in the absence of the pathfinding of their axons no direct evidence is available to support this suggestion.

It has been shown that in PFA-fixed samples, except of NOS, all of the NADPH-d requiring enzymes lost their catalytic activity, thus subsequent to PFA fixation only NOS could be stained with NADPH-d [13]. If the NADPH-d histochemistry is a marker of NOS-activity as was suggested earlier in both vertebrates [3,21] and invertebrates $[1,11]$ all of the SLABs and a few putative CSCs (tactile and pressure receptors) of earthworms are NOS containing structures. This finding strongly suggests the presence of $\mathrm{NO}$ as a neurotransmitter in the earthworms' nervous system and its involvement in the perception of both chemical and mechanical stimuli, moreover in the mediation of sensory information. However, in the investigated species another function of NO cannot fully be excluded. The high number of stained cells, which are not identical with any CSC or motoneuron, in addition to the occurrence of the highly stained axons in both the dorsomedial and dorsolateral interneuronal tracts, indicate that NO is also produced by interneurons. From this, we would predict an integrative central regulatory function of NO.

\section{ACKNOWLEDGEMENT}

The present scientific contribution is dedicated to the 650th anniversary of the foundation of the University of Pécs, Hungary.

\section{REFERENCES}

1. Bicker, G., Schmachtenberg, O., De Vente, J. (1996) The nitric oxide/cyclic GMP messenger system in olfactory pathways of the locust brain. Eur. J. Neurosci. 8, 2635-2643.

2. Csoknya, M., Takács, B., Koza, A., Dénes, V., Wilhelm, M., Hiripi, L., Kaslin, J., Elekes, K. (2005) Neurochemical characterization of nervous elements innervating the body wall of earthworms (Lumbricus, Eisenia): immunohistochemical and pharmacological studies. Cell Tissue Res. 321, 479-490.

3. Dawson, T. M., Bredt, D. S., Fotuhi, M., Hwang, P. M., Snyder, S. H. (1991) Nitric oxide synthase and neuronal NADPH diaphorase are identical in brain and peripheral tissue. Proc. Natl Acad. Sci. USA 88, 7797-7801. 
4. De Vries-Schoumacker, H. (1977) Fluorescence and ultrastructural localisation of aminergic neurons in the nerve cord of Eisenia foetida (Annelida, Oligochaeta). Cell Tissue Res. 185, 351-360.

5. Dorsett, D. A. (1978) Organization of the nerve cord. In: Mill, P. J. (ed.) Physiology of Annelids. Academic Press, London. pp. 115-156.

6. Elphick, M. R., Kemenes, G., Staras, K., O’Shea, M. (1995) Behavioral role for nitric oxide in chemosensory activation of feeding in a mollusc. J. Neurosci. 15, 7653-7664.

7. González, A. A., Muñoz, A., Muñoz, M., Marín, O., Arévalo, R., Porteros, A., Alonso, J. R. (1996) Nitric oxide synthase in the brain of a urodele amphibian (Pleurodeles walt) and its relation to catecholaminergic neuronal structures. Brain Res. 727, 49-64.

8. Günther, J. (1971) Mikroanatomie des Bauchmarks von Lumbricus terrestris. Z. Zellforsch. 60 , 826-849.

9. Günther, J. (1972) Giant motor neurons in the earthworm. Comp. Biochem. Physiol. 42, 967-973.

10. Günther, J., Walther, J. B. (1971) Funktionelle Anatomie der dorsalen Riesenfaser-Systeme von Lumbricus terrestris. Z. Morph. Tiere 70, 253-280.

11. Johansson, K. U. I., Carlberg, M. (1994) NADPH-diaphorase histochemistry and nitric oxide synthase activity in deuterocerebrum of the crayfish, Pacifastacus leniusculus (Crustacea, Decapoda). Neurosci. Lett. 649, 36-42.

12. Kitamura, Y., Naganoma, Y., Horita, H., Tsuji, N., Shimizu, R., Ogawa, H., Oka, K. (2001) Visualization of nitric oxide production in the earthworm ventral nerve cord. Neurosci. Res. 40, $175-181$.

13. Leake, L. D., Moroz, L. L. (1996) Putative nitric oxide synthase (NOS)-containing cells in the central nervous system of the leech, Hirudo medicinalis: NADPH-diaphorase histochemistry. Brain research $723,115-124$.

14. Licata, A., Ainis, L., Martella, S., Ricca, M. B., Licata, P., Lauriano, E. R., Zaccone, G. (2002) Immunohistochemical localization of nNOS in the skin and nerve fibers of the earthworm Lumbricus terrestris L. (Annelida Oligochaeta). Acta histochemica 104, 289-295.

15. Matsumoto, T., Nakane, M., Pollock, J. S., Kuk, J. E., Förstermann, U. (1993) A correlation between soluble brain nitric oxide synthase and NADPH-diaphorase activity is only seen after exposure of the tissue to fixative. Neurosci. Lett. 155, 61-64.

16. Mill, P. J. (1978) Sense organs and sensory pathways. In: Mill, P. J. (ed.) Physiology of annelids. Academic Press, London New York, pp. 63-114.

17. Molnár, L., Kiszler, G., Pollák, E., Deres, L. (2006) Distribution pattern of $\gamma$-amino butiric acid immunoreactive neural structures in the central and peripheral nervous system of the tubicid worm, Limnodrilus hoffmeisteri. Hydrobiologia 564, 33-43.

18. Muñoz, M., Muñoz, A., Marín, O., Alonso, J. R., Arévalo, R., Porteros, A., González, A. (1996) Topographical distribution of NADPH-diaphorase activity in the central nervous system of the frog, Rana perezi. J. Comp. Neurol. 367, 54-69.

19. Reglődi, D., Slezák, S., Lubics, A., Szelier, M., Elekes, K., Lengvári, I. (1997) Distribution of FMRFamide-like immunoreactivity in the nervous system of Lumbricus terrestris. Cell Tissue Res. 288, 575-582.

20. Rude, S. (1966) Monoamine-containing neurons in the nerve cord and the body wall of Lumbricus terrestris L. J. Comp. Neurol. 128, 397-412.

21. Schmidt, H. H. H. W., Gagne, G. D., Nakane, M., Pollock, J. S., Miller, M. F., Murad, F. (1992) Mapping of neural nitric oxide synthase in the rat suggests frequent co-localization with NADPH diaphorase but not with soluble guanylyl cyclase, and novel paraneural functions for nitrinergic signal transduction. J. Histochem. Cytochem. 40, 1439-1456.

22. Smeets, W. J. A. J., Alonso, J. R., González, A. (1997) Distribution of NADPH-diaphorase and nitric oxide synthase in relation to catecholaminergic neuronal structures in the brain of the lizard Gekko gecko. J. Comp. Neurol. 377, 121-141.

23. Spörhase-Eichmann, U., Winkler, M., Schürmann, F. W. (1998) Dopaminergic sensory cells in the epidermis of the earthworm. Nat. Wiss. 85, 547-550.

24. Vincent, S. R. (1992) Histochemistry of endogenous enzymes. In: Bolam, J. P. (ed.) Experimental Neuroanatomy. Oxford University Press, New York, pp. 153-171. 